\title{
COMÉRCIO INTRAINDUSTRIAL BRASILEIRO COM PAÍSES DESENVOLVIDOS E EM DESENVOLVIMENTO: ANÁLISE DO PERÍODO 1997-2013
}

\author{
J ean Carlo Amann* \\ Filipe Stona \\ Adriano Cristian Gewehr
}

\section{RESUMO}

Este estudo busca identificar a existência de um padrão no comércio intraindustrial (CII) do Brasil com países desenvolvidos e países em desenvolvimento. Para tal, utiliza-se o índice Grubel-Lloyd, a partir de dados de exportações e importações agregados ao nível de dois dígitos do Sistema Harmonizado, entre 1997 e 2013. O artigo não se limitou a uma análise bilateral, realizando esforços iniciais para estratificação de padrões do comércio de uma nação para com determinados contextos econômicos distintos. Indiferentemente da característica de comércio predominante no agregado entre duas nações, evidenciou-se que a existência de comércio intraindustrial pode se intensificar em determinadas indústrias, possivelmente a partir da participação em APCs. O estudo verificou possibilidade de CII em determinadas indústrias entre Brasil e as nações desenvolvidas, algo que sugere que o CII pode atuar como mecanismo para o progresso técnico. No entanto, observou-se a não existência de rigoroso padrão nos níveis de comércio intraindustrial entre Brasil e o grupo de países selecionados, considerando a amostra dos produtos analisados.

Palavras-chave: Comércio intraindustrial. Índice Grubel-Lloyd. Países desenvolvidos e em desenvolvimento.

\begin{abstract}
This study aims to identify an intra-industry trade (IIC) pattern in Brazil related to developing and developed countries. The analyses used the Grubel-Lloyd index, based on export and import data aggregated on two-digit Harmonized System (HS), between 1997 and 2013. The article was not limited to a bilateral analysis, performing initial efforts to the trade patterns of stratification for a nation with certain different economic contexts. The analysis has shown that intra-industry levels may intensify among some industries according to the countries engagement in PTAs. This study verified the possibility of IIC between Brazil and developed nations in some industries, suggesting that ICC can act as a mechanism for technical progress. However, it was observed the non-existence of a strict pattern in the levels of intra-industry trade between Brazil and both developed or developing countries, considering the sample of selected products.
\end{abstract}

Keywords: Intra-industry trade. Grubel-Lloyd index. Developed and developing countries.

JEL: F10; F14.

\footnotetext{
* Todos os autores da Universidade do Vale do Rio dos Sinos - UNISINOS, RS
} 


\section{INTRODUÇÃO}

Observa-se um crescente intercâmbio comencial de semelhantes itens manufaturados entre os países desde os anos 1960. Este movimento sugere contrariedade à existência somente de comércio interindustrial, como aponta a teoria tradicional das vantagens comparativas, a qual prevê que uma nação exportará produtos que utilizam intensivamente seus recursos abundantes e que são produzidos a baixos custos, eimportará bens que utilizam o fator de produção em que possui escassez e que são produzidos internamente de forma onerosa, em relação ao resto do mundo.

O comércio intraindustrial (CII) pode ser entendido como o fluxo comercial formado por simultâneas exportações e importações de uma mesma categoria de produtos (MARKUSEN; VENABLES, 2000). Greenaway e Milner (1983) destacam que o CII é importante por pelo menos duas razões. Primeiro, medir de forma acurada o comércio intraindustrial pode fornecer uma indicação da importância de determinantes do comércio internacional, além das proporções dos fatores relativos ${ }^{1}$. Segundo, ajustes na expansão do comércio podem ser mais fáceis quando a expansão toma a forma de um aumento intra-indústrias ao invés de um aumento entre indústrias ${ }^{2}$. Além do que, como pode ser observado no trabalho de Balassa (1977), depois que uma indústria manufatureira estiver estabelecida, a eliminação das medidas protecionistas no comércio entre países desenvolvidos parece não conseguir reverter os efeitos que essas medidas tiveram na composição industrial e a localização da indústria.

Assim, tem-se que o CII possibilita ganhos as economias de escala na produção industrial, dada a diminuição dos custos unitários com o aumento da produção, e ganhos aos consumidores sob a ótica da gama de escolhas, benefícios não levados em conta pelas teorias tradicionais (HIDALGO, 1993a). Pondera-se, ainda, que indústrias e mercados que fornecem um melhor ambiente para o crescimento das corporações multinacionais caracterizam-se por maior proporção de comércio intraindustrial. De tal modo, o CII com países desenvolvidos pode encontrar vantagens ao se especializar em bens de consumo e bens intermediários com uma demanda por trabalho não especializado; por isso, formas de integração econômica e acordos tarifários tendem a ser fontes de CII. Países com similares níveis de desenvolvimento encontram facilmente especialização intra-indústria, através de trocas de bens de consumo, enquanto a

\footnotetext{
1 Os autores exemplificam destacando a importância de fatores como a preferência pela diversidade e dos custos decrescentes, os quais não são contemplados pelo modelo de HeckscherOhlin. Assim, os postulados desta abordagem perdem valor na tentativa de explicar o CII.

${ }^{2}$ Krugman (1981) demonstrou que o comércio intraindustrial impõe menos problemas de ajustes na estrutura em reação ao comércio entre indústrias. Ou seja, diferente do que argumentava a teoria das vantagens comparativas quanto a haver especialização intersetorial entre os países, "ao invés de haver especialização intersetorial entre os países [...], as economias nacionais pareciam preservar sua ampla estrutura industrial e se especializam predominantemente em um nível intrasetorial", como explicado por Pinto et al. (2012, p. 2).
} 
diferença relativa nos preços contribui para o comércio intraindustrial (KÁDÁR, 1981).

Dentre os motivos que possibilitam o CII entre países, Scott (1975) e Loertscher e Wolter (1980) abordam que tal comércio está diretamente relacionado ao estágio de desenvolvimento dos países, ao tamanho dos mercados internos e às barreiras existentes ao comércio. Quanto mais avançado o estágio de desenvolvimento dos países e maiores os mercados internos, na presença de poucas barreiras comerciais, mais intenso torna-se o CII. No mesmo sentido, Helpman (1987) argumenta que, quanto maior for a semelhança do PIB per capita entre os países, maior intensidade de CII deve haver. Países importam e exportam muitos produtos similares, que não são iguais, sendo substitutos próximos em consumo e produção: a razão mais relevante para esse tipo de comércio está nas economias de escala e na diferenciação dos produtos. A especialização em uma peça da cadeia produtiva permite que uma empresa adquira vantagem competitiva. O comércio intraindustrial destaca a relevância das economias de escala e da competição imperfeita (SCOTT, 1975).

Este estudo busca identificar a existência de um padrão no comércio intraindustrial do Brasil com países desenvolvidos (Estados Unidos eAlemanha) e com países em desenvolvimento (Argentina, México e China). Como será observado na seção de trabalhos da área, existem diversos trabalhos que evidenciam a existência deCII entre o Brasil e os países selecionados, no entanto, são escassas as análises que organizam conjuntamente os países em desenvolvidos e em desenvolvimento. Tal agrupamento justifica-se pela importância do estágio de desenvolvimento para a consolidação do CII, com apontado por Scott (1975) e Loertscher e Wolter (1980). Quanto mais avançado o estágio de desenvolvimento dos países, e maiores os mercados internos, na presença de poucas barreiras comerciais, mais intenso torna-se o CII.

Para realização dessa análise, será utilizado o índice Grubel-Lloyd que, apesar de seus defeitos, discutidos na seção metodológica, ainda é considerado pela literatura como uma forma adequada para a mensuração do CII. Os dados de exportações e importações são agregados ao nível de dois dígitos do Sistema Harmonizado (SH), entre 1997 e 2013, vide disponibilidade de informações do AliceWeb ${ }^{3}$. São analisados setores de cunho industrial, como produtos farmacêuticos, reatores nucleares, caldeiras, máquinas, aparelhos einstrumentos mecânicos, máquinas, aparelhos e materiais elétricos, veículos automóveis, tratores e outros veículos terrestres, aeronaves e aparelhos espaciais e instrumentos e aparelhos de ótica e médico-cirúrgicos. Entender em maior profundidade o CII brasileiro com países desenvolvidos e em desenvolvimento é fundamental na definição de estratégias de política comercial, principalmente, quando vislumbrado a participação em acordos preferenciais de comércio, sejam eles de âmbito regional, ou extra-regional.

\footnotetext{
${ }^{3}$ Sistema de Análise das Informações de Comércio Exterior.
} 
O artigo está dividido em cinco diferentes seções, iniciando por esta introdução. A segunda seção está voltada a discutir a teoria de comércio intraindustrial. A terceira seção demonstra evidências empíricas do CII brasileiro. Os aspectos metodológicos são apresentados na quarta seção, com os resultados sendo apresentados na seção seguinte. A sexta seção, por fim, conclui a pesquisa.

\section{A TEORIA ASSOCIADA COM O COMÉRCIO INTRAINDUSTRIAL}

Uma das primeiras menções a existência de comércio intraindustrial está no trabalho de Hildgert (1935), tornando-se mais comum com a formação da Comunidade Econômica Europeia em 1957. Verdoorn (1960), Braze (1961) e Balassa (1965) perceberam uma tendência crescente de comércio intra-industrial na presença de um acordo preferencial de comércio, entretanto, estes primeiros estudos preocupavam-se mais em relatar a existência de CII, a explicar suas causas e efeitos.

Quanto à avaliação dos níveis de CII de um país, Balassa (1966) mostrou-se pioneiro em formalizar um método para tal fim. Grubel e J ohnson (1967), no entanto, avaliam que a formulação de Balassa (1966) está mais voltada a medir o fluxo de comércio interindustrial, isto é, o tipo de comércio Heckscher-Ohlin (HO). Grubel e Lloyd (1975), posteriormente, desenvolveram uma metodologia para a estimação dos níveis de CII, que muito se difundiu para este tipo de análise.

Segundo Linder (1961), o CII entre os países relaciona-se com as preferências distintas dos consumidores. Estas diferentes preferências, quando associadas com similaridades na renda, gerariam maior fluxo de comércio intra-industrial. Outra possiblidade levantada pela literatura remete ao argumento de que os ciclos do produto, estabelecidos por Vernon (1966), poderiam produzir comércio intra-industrial (SAWYER; SPRINKE, 2012).

Ainda, além do entendimento de Scott (1975) e Loertscher e Wolter (1980), que o CII estaria relacionado com o nível de desenvolvimento das economias, Helpman (1987) argumenta que, quanto maior for a semelhança do PIB per capita entre os países, maior intensidade de CII deve haver. Esses argumentos demonstram a relevância de trabalhar com os países agrupados em desenvolvidos e em desenvolvimento, tal como proposto neste trabalho. Além disso, países importam e exportam muitos produtos similares, que não são iguais, sendo substitutos próximos em consumo e produção: a razão mais relevante para esse tipo de comércio está nas economias de escala e na diferenciação dos produtos. A especialização em uma peça da cadeia produtiva permite a uma empresa, por exemplo, adquirir vantagens competitivas. O comércio intraindustrial destaca a relevância das economias de escala e da competição imperfeita (SCOTT, 1975). De forma mais organizada, Lloyd (2004) formou quatro grupos de explicações para o CII.

O primeiro grupo explica o CII pela consideração de que as economias de escala são um aspecto difundido na economia mundial, e que há uma preferência dos 
consumidores pela variedade. Os produtos podem ser "horizontalmente diferenciados", i.e., terem qualidade e preço semelhantes com características diferentes - tanto no sentido de Krugman (1979), quanto Lancaster (1979) - ou "verticalmente diferenciados", quando possuem diferença de qualidade, como exposto por Falvey (1981). Esse fato leva ao entendimento desenvolvido por Armington (1969), de que bens produzidos por uma indústria em diferentes países são substitutos imperfeitos, mas podem ser agregados na função de utilidade do consumidor.

Existem também modelos de CII em produtos homogêneos, onde se consideram o fator da diferenciação. Para explicar esse tipo de CII, Brander (1981) considerou a discriminação de preços e competição de Cournot. Assim, Lloyd (2004) explica que a menor fatia de mercado das empresas estrangeiras leva a uma menor percepção de elasticidade de demanda, levando a uma penetração mútua nos mercados, apesar da existência de custos de transporte. Esse modelo ficou conhecido como "dumping recíproco". Ainda, uma expansão recente nesse sentido foi feita por Anam e Chiang (2003), ao considerarem que a aversão das firmas ao risco levava a diversificação entre mercados, a menos que os custos de transporte fossem exageradamente altos.

O terceiro grupo da estrutura construída por Lloyd (2004) justifica o comércio entre produtos intermediários. Nesse sentido, destaca-se Dixit e Grossman (1982), que formulam um modelo no qual se mantêm as premissas de retornos constantes de escala e de dois bens finais homogêneos de Hecksher-Ohlin. Os autores consideram a comercialização de bens intermediários por bens finais de outra indústria como um tipo de comércio intraindustrial, e capturam características do comércio internacional contemporâneo. Esse modelo representa, de certa forma, o problema da agregação, pois os países estão comercializando bens intermediários por bens finais ${ }^{4}$.

Finalmente, há um quarto grupo de modelos com multinacionais. Lloyd (2004) demonstra que esses modelos consideram um cenário onde um dos produtores é uma empresa multinacional, que opera firmas em mais de um país, havendo comércio intraindustrial no sentido de comércio intra-firma. Assim, empresas multinacionais poderiam penetrar em mercados internacionais com investimentos diretos externos, aumentando o comércio intra-industrial no sentido abordado anteriormente, com transação de bens intermediários e finais.

Evidencia-se, assim, diversas possiblidades de recortes teóricos, tanto na captação, quanto no entendimento das causas do comércio intra-industrial. Após, são apresentados estudos empíricos que observaram o CII para o Brasil.

\section{EVIDÊNCIAS EMPÍRICAS PARA O BRASIL}

\footnotetext{
${ }^{4}$ Como exemplo, cita-se a compra de peças para veículos e venda de carros. Dependendo da agregação dos dados, pode haver ou não comércio intraindustrial nessa abordagem.
} 
Hidalgo (1993b) buscou identificar os impactos da mudança na política comercial e na estratégia de substituição de importações no Brasil. Em análise do período 1978-1987, verificou que o CII brasileiro teve participação de $40 \%$ do comércio total de manufaturados. Sua pesquisa demonstrou que, nestes anos, o CII era mais intenso em produtos diferenciados, em setores com salários maiores, com menos barreiras tarifárias. Para o autor, "o conhecimento mais completo desse tipo de comércio requer o estudo das características das indústrias que apresentam essa modalidade de comércio, assim como das características dos países que participam do intercâmbio comercial" (HIDALGO, 1993b, p. 244).

Vasconcelos (2003) verificou que, em função da criação do MERCOSUL, o CII multilateral geral brasileiro cresceu 44\%, entre 1991 e 1995, e 100\%, entre 1995 e 1998. Suas conclusões apontaram quea participação do Brasil no bloco aumentou o intercâmbio de produtos de mesmo segmento, o que, por sua vez, sugere aumento da especialização da produção e aumento no CII, a partir da liberalização comercial intrabloco. Este estudo contribuiu para comprovar que, na ótica da demanda, o CII eleva o bem- estar social (efeito variedade), e na ótica da oferta, estimula a especialização das firmas em linhas produtivas específicas.

O trabalho de Silva et al. (2010) demonstrou que, entre 1990 e 1994, o comércio total entre Brasil e Argentina ainda era caracterizado, principalmente, por fluxos interindustriais. No entanto, o estudo apontou que, com a criação do MERCOSUL, houve uma migração deste perfil para o tipo de fluxo comercial intraindustrial, sinalizando que a participação em acordos regionais de comércio influencia para o aumento dos índices de CII, no comércio entre as economias integradas. Montoro et al. (2005) observaram que a relação Brasil-MERCOSUL, de forma agregada, apresenta níveis de CII elevados para o setor de manufaturados, mas índices bastante baixos para os demais setores.

As evidências na relação Brasil-Argentina também são sumarizadas no estudo de Carmo e Bittencourt $(2013)^{5}$, que apresenta maiores índices de CII nas indústrias química e têxtil, de transporte, de plásticos e borracha, de máquinas e materiais elétricos. À medida que se intensificaram as relações comerciais entre os dois países, verificou-se que ocorreu uma maior similaridade na qualidade dos produtos, processo que foi iniciado, basicamente, entre 2003 e 2009. No início da série analisada, a qualidade dos produtos exportados pelo Brasil era inferior a qualidade dos produtos argentinos. A pesquisa de Carmo e Bittencourt (2013) constatou, ainda, que entre 1995-2002, o CII ocorreu, principalmente, em produtos diferenciados em qualidade, para os quais o comércio intraindustrial vertical $^{6}$ representou em torno de $70 \%$ do comércio intraindustrial total.

${ }^{5}$ A pesquisa destes autores observa as variáveis diferenciação e qualidade, pois se desagregou o CII em níveis horizontal (essencialmente, economias de escala) evertical (exclusivo em vantagens comparativas).

6 O comércio intraindustrial pode ser qualificado em horizontal e em vertical. O CII horizontal refere-se a exportações e importações em um mesmo setor, com diferenciações dos produtos comercializados, mas em semelhantes estágios de processamento e tecnologia envolvida, enquanto o CII vertical refere-se a exportações e importações em um mesmo setor, mas em 
Posteriormente, entre 2003-2009, observou-se alteração, pois o CII passou a ser mais intenso nos produtos diferenciados em variedade, uma vez que as trocas mais intensas se deram em produtos horizontalmente diferenciados.

Moreira e De Paula (2010) analisaram a intensidade dos fluxos de CII entre Brasil-Estados Unidos (EUA), de 1997 a 2007. Este estudo demonstra a relevância do CII para o fluxo comercial do país, e sua importância como mecanismo para o progresso técnico. A maior parte do CII existente entre BrasilEUA é constituído de produtos industriais intermediários, ou seja, itens que são insumos para confecção de outros bens. Os resultados encontrados corroboram a pesquisa de Hidalgo (1993b), em que se destacaram, na mesma proporção, as indústrias química, de máquinas, aparelhos e material elétrico e de materiais de transporte. Observando-se os índices GL destas indústrias, a pesquisa ratificou os pressupostos de Loertscher eWolter (1980), de que, quanto mais desenvolvido um setor, maior é seu índice GL esperado.

Caldarelli e Miranda (2009), em análise do comércio entre Brasil e China, no período 1990-2007, constataram que: i) a intensificação de CII entre os países está mais em produtos do agronegócio; ii) pautas como químicos, ferro, aço, automóveis, aeronaves e reatores nucleares mantiveram e intensificaram suas relações intraindustriais. Apesar destas constatações, o comércio bilateral BrasilChina ainda seria mais caracterizado pelo tipo interindustrial, quando comparado aos perfis comenciais entre Brasil-EUA ou Brasil-União Europeia. A pesquisa de Caldarelli e Miranda (2009) aponta, ainda, que o aumento do CII atua como mecanismo de estímulo para elaboração de medidas protecionistas.

Referente aos efeitos sociais e econômicos, Campos et al. (2007) propuseram avaliar os efeitos que o CII traz sobre a remuneração da mão-de-obra nas indústrias, tendo como base o período 1997-2002. A constatação é de que as firmas brasileiras exportadoras remuneram melhor que as não exportadoras, em especial, nas de porte com no máximo 99 trabalhadores. Para Campos et al. (2007), haveria uma correlação positiva entre CII e as desigualdades salariais do país. Em análise com o objetivo de verificar sea hipótese de ajuste suavizado seria válida para o caso brasileiro, no período de 1997-2008, Pinto et al. (2012) demonstraram o que prediz a teoria: existência de relação inversa entre CII e deslocamento do fator trabalho no fluxo de comércio externo, ou seja, há um menor custo para as empresas ao ocorrer uma mudança no cenário comercial desse tipo.

Alguns trabalhos recentes, ainda, merecem destaque. Bittencourt et al. (2015) investigaram o CII brasileiro com os países da OCDE, identificando seus determinantes, e realizando uma decomposição entre comércio intraindustrial horizontal (CIIH) evertical (CIIV). Na pesquisa, os autores identificaram maiores volumes e índices de CII, respectivamente, com Estados Unidos e México. Como esperado, os índices de CIIV tiveram amplitude maior, dadas as diferenças de

produtos de diferentes estágios de industrialização, com distintas qualidades (VASCONCELOS, 2003; BALTAR, 2008). 
renda entre os países comparados e, ainda, percebeu-se que a qualidade das exportações brasileiras foi inferior a das importações pelo país. Borges e Fraga (2015), por outro lado, analisaram o comércio internacional entre a Região Sul do Brasil e os demais membros do BRICS. Para alguns setores, como alimentos, fumos e bebidas, foram verificados índices GL que remetem fortemente ao comércio interindustrial, evidenciando que parte da pauta da Região Sul, com os demais quatro países do grupo, é orientada pelas vantagens comparativas.

A partir da revisão dos estudos empíricos, nota-se que, apesar da relevante quantidade de estudos sobre o CII brasileiro, são poucos os que adotam claramente uma composição de países visando comparar a relação de comércio intraindustrial do Brasil entre países desenvolvidos e em desenvolvimento, reforçando a abordagem aqui adotada. Após a revisão empírica acerca do CII brasileiro com alguns países desenvolvidos e outros em desenvolvimento, prossegue-se com o método que busca estimar o nível de comércio intraindustrial do Brasil com as nações da amostra, o índice Grubel-Lloyd.

\section{METODOLOGIA E TRATAMENTO DOS DADOS}

O comércio intraindustrial entre países pode ser medido por meio de diferentes maneiras e abordagens. Uma das formas mais tradicionais para analisar este tipo de comércio, como apontam Greenaway e Milner (1983), Egger et al. (2007) e Baltar (2008), foi proposta por Grubel e Lloyd (1975) (índice Grubel-Lloyd ou, simplesmente, índice GL).

Este método consiste em determinar a intensidade do comércio intraindustrial pela sobreposição entre exportações e importações em um determinado setor produtivo, a partir do fluxo comercial entre diferentes países (FONTAGNÉ; FREUDENBERG, 1997). Ao nível de cada indústria, o índice é expresso por meio da seguinte equação (VASCONCELOS, 2003):

$G L_{i}=\frac{\left(X_{i}+M_{i}\right)-\left|X_{i}-M_{i}\right|}{\left(X_{i}+M_{i}\right)}$

Em que:

$G L_{i}$ é igual ao índice GL para o setor $i$;

$X_{i}$ e $M_{i}$ representam, respectivamente, as exportações e importações no setor $i$;

$\left(X_{i}+M_{i}\right)-\left|X_{i}-M_{i}\right|$ é igual ao comércio intra-indústria no setor $i$;

$\left|X_{i}-M_{i}\right|$ é igual ao comércio interindustrial no setor $i$;

$\left(X_{i}+M_{i}\right)$ é igual ao comércio total no setor $i$.

O índice GL situa-se no intervalo entre zero e a unidade. Se $G L_{i}=0$, todo o comércio será do tipo interindustrial (alternativamente, do tipo HeckscherOhlin), e se $G L_{i}=1$, todo o comércio será na forma intraindustrial (HIDALGO, 
1993b; BALTAR, 2008). Quando o resultado indicar comércio inteiramente interindustrial, as exportações ou as importações do setor $i$ são iguais a zero, e quando indicar comércio inteiramente intraindustrial, o valor das exportações é igual ao das importações, para a indústria analisada (VASCONCELOS, 2003).

Alguns dos defeitos do índice GL estão relacionados a agregação dos dados e no ajustamento dos desequilíbrios de comércio. Os perfis de comércio, a partir do índice Grubel-Lloyd, guardam relação direta com o nível de agregação setorial dos dados de exportações e importações. Como destacado por Finger (1975) e Rayment (1983), a agregações em níveis altos geram resultados de maior comércio intra-industrial, fazendo com que o comércio intraindustrial torne-se um produto das agregações nos sistemas de categorização do comércio. Quando o nível de agregação setorial é demasiadamente elevado, os resultados estarão enviesados, indicando CII superestimado; por outro lado, quando o nível de desagregação for muito alto, tendem a indicar CII subestimado ${ }^{7}$. Andressen (2003), acerca desta discussão, aborda que uma consolidação elevada pode considerar produtos razoavelmente distintos em apenas um código, de modo que uma consolidação menos elevada poderia corrigir tal problema, ao separar itens de uma mesma indústria, mas com características particulares, em diferentes classificações.

Outra desvantagem na utilização do GL baseia-se no fato de que, caso não exista equilíbrio no comércio, o GL nunca será igual a 1,00. Aquino (1978) tentou corrigir a questão do desequilíbrio de pagamentos agregados, sendo criticado por acabar gerando ainda mais distorções (GREENAWAY E MILNER, 1983). No mesmo sentido, Eagger et al. (2007) argumentam que o GL não considera o repatriamento de lucros de empresas multinacionais, subestimando o CII. Todavia, apesar das propostas existentes na literatura, não há consenso sobre o procedimento metodológico mais adequado para corrigir essa questão, tornando razoável a utilização do GL para mensuração do comércio intra-indústrias.

Apesar da agregação setorial em estudos prévios usualmente seguir a nomenclatura SITC $^{8}$, a três dígitos ${ }^{9}$, este artigo estrutura-se a partir da classificação $\mathrm{SH}^{10}$, a dois dígitos. Percebe-se que a agregação a dois dígitos do sistema harmonizado pode ser considerada como demasiadamente agregada, entretanto, é válido ressaltar que tal agregação já oportuniza 99 diferentes possibilidades de investigação, as quais abrangem produtos razoavelmente heterogêneos uns dos outros. As áreas de investigação, mediante valores nominais de exportações e importações anuais, foram definidas por abordagem qualitativa: em observação à estrutura do SH, foram selecionados setores que, acredita-se, possuem maiores graus de tecnologia e complexidade produtiva são eles: produtos farmacêuticos (capítulo 30 do SH); reatores nucleares, caldeiras, máquinas, aparelhos e instrumentos mecânicos (cap. 84); máquinas,

\footnotetext{
7 Ver Greenway e Milner (1983), Hidalgo (1993b) e Moreira e de Paula (2010).

${ }^{8}$ Standard International Trade Classification.

9 Dentre outros, ver Egger et al. (2007), Andressen (2003) e Vasconcelos (2003).

10 Sistema harmonizado (HS - Harmonized system).
} 
aparelhos e materiais elétricos (cap. 85); veículos automóveis, tratores e outros veículos terrestres (cap. 87); aeronaves e aparelhos espaciais (cap. 88); instrumentos e aparelhos de ótica e médico-cirúrgicos (cap. 90).

Investigam-se os fluxos bilaterais do comércio brasileiro com Argentina, China e México (conjunto de países em desenvolvimento), e com Alemanha e Estados Unidos (conjunto de países desenvolvidos), entre os anos 1997-2013, considerada a disponibilidade de dados em ALICEWEB (2016). Estes países, em 2013, estiveram no grupo de principais parceiros comerciais do Brasil, o que configura uma amostra razoável à análise ${ }^{11}$. Adicionalmente, cabe ressaltar que os capítulos selecionados representaram parcelas significativas do comércio bilateral Brasileiro com os demais países da amostra, vide análise ao Apêndice $\mathrm{B}^{12}$.

Na seção seguinte, em um primeiro momento, investiga-se o comércio brasileiro, com os países selecionados, ao nível de seções do SH e, posteriormente, os perfis bilaterais de comércio, por meio do índice GL.

\section{EVIDÊNCIAS DO COMÉRCIO INTRAINDUSTRIAL BRASILEIRO}

Ao se analisar o perfil comercial do Brasil com o conjunto de países selecionados, a partir dos dados em AliceWeb (2016), identificou-se que parte preponderante das trocas concentra-se em um número restrito de setores. Os grupos de produtos correspondentes às seções V13, VI ${ }^{14}$, XVI ${ }^{15}$ e XVII ${ }^{16}$ do SH, predominantemente, figuraram como os principais no comércio com Argentina, México, Alemanha e Estados Unidos. O perfil com a China mostrou-se uma exceção, dado que a seção II ${ }^{17}$ teve relevância, ao passo que a seção XVI não se demonstrou importante. O comércio bilateral brasileiro, com os países selecionados, ao nível de seções do SH, consta na Tabela 01.

${ }^{11}$ O Apêndice A demonstra a participação dos países na corrente de comércio brasileira, em 2013. 12 Com México, por exemplo, os capítulos selecionados representaram mais de $63 \%$ de todo o comércio bilateral no período 1997-2013; com Alemanha e Argentina, cerca de 47\%; com EUA e China, respectivamente, em torno de $40 \%$ e $28 \%$.

13 Produtos minerais.

14 Produtos das indústrias químicas ou das indústrias conexas.

15 Máquinas e aparelhos elétricos.

${ }_{16}$ Automóveis, aeronaves, tratores e embarcações.

${ }_{17}$ Produtos do reino vegetal. 
TABELA O 1 - COMÉRCIO BRASILEIRO COM OS PAÍSES SELECIONADOS, POR SEÇÃO DO HS (EM \%), ENTRE 1997 E 2013

\begin{tabular}{c|c|c|c|c|c}
\hline Seções & Alemanha & Argentina & China & EUA & México \\
\hline I & $1,70 \%$ & $2,02 \%$ & $0,71 \%$ & $0,54 \%$ & $0,01 \%$ \\
\hline II & $7,77 \%$ & $8,53 \%$ & $16,25 \%$ & $2,93 \%$ & $1,40 \%$ \\
\hline III & $0,11 \%$ & $0,37 \%$ & $1,45 \%$ & $0,11 \%$ & $0,07 \%$ \\
\hline IV & $4,82 \%$ & $2,57 \%$ & $2,23 \%$ & $4,14 \%$ & $1,63 \%$ \\
\hline V & $7,95 \%$ & $9,98 \%$ & $26,62 \%$ & $12,90 \%$ & $2,28 \%$ \\
\hline VI & $16,56 \%$ & $9,07 \%$ & $4,87 \%$ & $13,15 \%$ & $12,06 \%$ \\
\hline VII & $4,01 \%$ & $7,10 \%$ & $2,14 \%$ & $5,34 \%$ & $4,61 \%$ \\
\hline VIII & $0,29 \%$ & $0,27 \%$ & $1,51 \%$ & $0,59 \%$ & $0,63 \%$ \\
\hline XX & $0,63 \%$ & $0,38 \%$ & $0,34 \%$ & $2,08 \%$ & $0,50 \%$ \\
\hline X & $1,35 \%$ & $2,21 \%$ & $2,42 \%$ & $2,77 \%$ & $0,55 \%$ \\
\hline XI & $0,71 \%$ & $2,75 \%$ & $4,40 \%$ & $1,39 \%$ & $1,20 \%$ \\
\hline XII & $0,48 \%$ & $0,69 \%$ & $0,49 \%$ & $1,96 \%$ & $0,56 \%$ \\
\hline XIII & $0,85 \%$ & $0,66 \%$ & $0,83 \%$ & $1,82 \%$ & $1,60 \%$ \\
\hline XIV & $1,07 \%$ & $0,03 \%$ & $0,10 \%$ & $1,14 \%$ & $0,61 \%$ \\
\hline XV & $6,37 \%$ & $5,91 \%$ & $5,47 \%$ & $9,32 \%$ & $9,55 \%$ \\
\hline XVI & $29,01 \%$ & $13,14 \%$ & $24,32 \%$ & $25,09 \%$ & $23,77 \%$ \\
\hline XVII & $11,44 \%$ & $33,02 \%$ & $2,35 \%$ & $9,95 \%$ & $36,82 \%$ \\
\hline XVIII & $4,04 \%$ & $0,65 \%$ & $1,93 \%$ & $3,41 \%$ & $1,48 \%$ \\
\hline XIX & $0,07 \%$ & $0,02 \%$ & $0,00 \%$ & $0,25 \%$ & $0,01 \%$ \\
\hline XX & $0,71 \%$ & $0,61 \%$ & $1,53 \%$ & $0,92 \%$ & $0,60 \%$ \\
\hline XXI & $0,06 \%$ & $0,03 \%$ & $0,03 \%$ & $0,19 \%$ & $0,04 \%$ \\
\hline
\end{tabular}

Fonte: elaborado pelos autores. Origem bruta dos dados: ALICEWEB (2016).

A partir da Tabela 01, percebe-se que um considerável volume de comércio é englobado pelo grupo de bens manufaturados. As seções XVI e XVII, que representam máquinas e aparelhos elétricos, automóveis, aeronaves, tratores e embarcações, foram responsáveis por cerca de $60,59 \%$ do comércio acumulado do Brasil com México, 46,16\% com Argentina, 40,45\% com Alemanha e 35,05\% com os Estados Unidos. No comércio com a China, a participação destas seções foi menor (26,66\%), em virtude de maior fluxo bilateral de itens não industriais, como produtos do reino vegetal (seção II) e produtos minerais (seção V).

O Brasil manteve posição de exportador líquido nas seções XVI e XVII com o conjunto de países em desenvolvimento ${ }^{18}$ no período acumulado, com um saldo comercial positivo em torno de US $\$ 43$ bilhões ${ }^{19}$. O fluxo de trocas com o México foi o que se mostrou mais homogêneo, com exportações em nível mais semelhante ao das importações, caracterizando um perfil mais aproximado do comércio intraindustrial que interindustrial. Com a China, o Brasil assumiu posição de importador líquido, com saldo comercial negativo em torno de US\$103 bilhões, considerado o período 1997-2013. Ao se analisar o conjunto de

18 Excetuando a China.

${ }^{19}$ Dados da balança comercial brasileira com os demais países podem ser vistos no Apêndice C. 
países desenvolvidos, o saldo comencial brasileiro acumulado mostrou-se negativo, em aproximadamente US $\$ 89$ bilhões.

Mesmo que os perfis de comércio tenham sido brevemente demonstrados ao nível de um dígito do SH (seções), a análise mais apurada sobre o CII do Brasil com os parceiros definidos ocorre ao nível de dois dígitos (capítulos). Desta forma, em sequência, analisa-se o perfil de comércio bilateral brasileiro com cada país da amostra, pelo índice Grubel-Lloyd.

No fluxo bilateral Brasil-Argentina (Tabela 02), percebe-se elevado nível de comércio intraindustrial, na média acumulada do período, para os capítulos 30, 87 e 90. Estes três casos demonstraram CII crescente no intervalo 1997-2013, de modo que, nos três capítulos, o Brasil foi exportador líquido.

\begin{tabular}{|c|c|c|c|c|c|c|c|c|c|c|c|c|c|c|c|c|c|c|}
\hline Cap. & 1997 & 1998 & 1999 & 2000 & 2001 & 2002 & 2003 & 2004 & \begin{tabular}{|l|}
2005 \\
\end{tabular} & \begin{tabular}{|l|}
2006 \\
\end{tabular} & 2007 & \begin{tabular}{|l|}
2008 \\
\end{tabular} & 2009 & 2010 & 2011 & 2012 & 2013 & Média $^{1}$ \\
\hline 30 & 0,774 & 0,887 & 0,961 & 0,972 & 0,976 & 0,954 & 0,923 & 0,982 & 0,914 & 0,828 & 0,835 & 0,916 & 0,848 & 0,922 & 0,876 & 0,986 & 0,967 & 0,918 \\
\hline 84 & 0,692 & 0,597 & 0,627 & 0,634 & 0,611 & 0,947 & 0,569 & 0,447 & 0,388 & 0,363 & 0,384 & 0,432 & 0,554 & 0,446 & 0,371 & 0,479 & 0,568 & 0,530 \\
\hline 85 & 0,611 & 0,596 & 0,434 & 0,286 & 0,549 & 0,890 & 0,430 & 0,268 & 0,206 & 0,186 & 0,180 & 0,184 & 0,161 & 0,187 & 0,238 & 0,256 & 0,278 & 0,311 \\
\hline 87 & 0,908 & 0,873 & 0,950 & 0,931 & 0,676 & 0,577 & 0,759 & 0,564 & 0,595 & 0,726 & 0,838 & 0,866 & 0,899 & 0,997 & 0,935 & 0,966 & 0,946 & 0,844 \\
\hline 88 & 0,017 & 0,045 & 0,036 & 0,183 & 0,057 & 0,000 & 0,000 & 0,024 & 0,062 & 0,000 & 0,000 & 0,174 & 0,127 & 0,000 & 0,002 & 0,003 & 0,006 & 0,041 \\
\hline 90 & 0,359 & 0,431 & 0,490 & 0,853 & 1,000 & 0,883 & 0,959 & 0,986 & 0,884 & 0,752 & 0,743 & 0,705 & 0,684 & 0,582 & 0,485 & 0,516 & 0,457 & 0,685 \\
\hline Média $^{2}$ & 0,560 & 0,572 & 0,583 & 0,643 & 0,645 & 0,709 & 0,607 & 0,545 & 0,508 & 0,476 & 0,497 & 0,546 & 0,545 & 0,523 & 0,485 & 0,534 & 0,537 & - \\
\hline
\end{tabular}

Considerando a seleção de capítulos do SH, o comércio bilateral Brasil-Argentina, na média acumulada do período, mostrou-se mais orientado ao caráter intraindustrial que interindustrial, observado o índice GL geral de 56\% nas indústrias selecionadas. Montoro et al. (2005), Silva et al. (2010) e Carmo e Bittencourt (2013) já haviam evidenciado que, de forma geral, o comércio entre Brasil e Argentina é caracterizado, principalmente, pelo tipo de comércio intraindustrial.

O fluxo bilateral Brasil-China é evidenciado na Tabela 03. Nenhum dos capítulos, na média acumulada do período, excedeu $50 \%$ do intercâmbio comercial. Os setores com maior nível de CII, na média dos anos, foram os abrangidos pelos capítulos 30, 87 e 84, respectivamente. Em adição, percebeu-se que somente o cap. 30 apresentou índices GL crescentes no período observado, e que o Brasil foi importador líquido nos três setores.

Uma área de destaque, no que se refere ao nível de CII, foi o de veículos automóveis, tratores e outros veículos terrestres (cap. 87), principalmente nos anos iniciais da análise. Entre 1997e 2000, conforme a Tabela 03, o índice oscilou entre 0,619 e 0,995, denotando um elevado volume de comércio intra-indústria no segmento. Entretanto, destaca-se um acentuado decréscimo no índice GL deste capítulo a partir de 2006, muito devido a intensiva entrada de montadoras chinesas no mercado brasileiro que correu neste período, de forma que o Brasil 
se tornou importador líquido em relação à China nesta pauta, com saldo comercial negativo em torno de US\$4,75 bilhões.

TABELA O3 - ÍNDICES GL, POR CAPÍTULOS DO SH, NO COMÉRCIO ENTRE BRASIL E CHINA (1997-20 13)

\begin{tabular}{|c|c|c|c|c|c|c|c|c|c|c|c|c|c|c|c|c|c|c|}
\hline Cap. & 1997 & 1998 & 1999 & 2000 & 2001 & 2002 & 2003 & 2004 & 2005 & 2006 & 2007 & 2008 & 2009 & 2010 & 2011 & 2012 & 2013 & Média' \\
\hline 30 & 0,198 & 0,191 & 0,276 & 0,135 & 0,978 & 0,797 & 0,784 & 0,562 & 0,068 & 0,215 & 0,253 & 0,216 & 0,326 & 0,776 & 0,554 & 0,580 & 0,649 & 0,465 \\
\hline 84 & 0,429 & 0,267 & 0,296 & 0,309 & 0,654 & 0,800 & 0,978 & 0,639 & 0,508 & 0,334 & 0,182 & 0,146 & 0,088 & 0,081 & 0,078 & 0,088 & 0,067 & 0,310 \\
\hline 85 & 0,070 & 0,050 & 0,064 & 0,068 & 0,236 & 0,262 & 0,161 & 0,082 & 0,065 & 0,063 & 0,028 & 0,028 & 0,043 & 0,020 & 0,021 & 0,019 & 0,015 & 0,073 \\
\hline 87 & 0,916 & 0,995 & 0,619 & 0,993 & 0,221 & 0,336 & 0,203 & 0,586 & 0,760 & 0,639 & 0,318 & 0,088 & 0,080 & 0,070 & 0,041 & 0,090 & 0,067 & 0,410 \\
\hline 88 & 0,000 & 0,000 & 0,000 & 0,000 & 0,002 & 0,162 & 0,000 & 0,000 & 0,000 & 0,013 & 0,000 & 0,000 & 0,000 & 0,003 & 0,000 & 0,000 & 0,000 & 0,004 \\
\hline 90 & 0,039 & 0,079 & 0,090 & 0,090 & 0,171 & 0,147 & 0,139 & 0,085 & 0,062 & 0,051 & 0,050 & 0,028 & 0,068 & 0,046 & 0,072 & 0,070 & 0,069 & 0,098 \\
\hline Média $^{2}$ & 0,275 & 0,264 & 0,224 & 0,266 & 0,377 & 0,417 & 0,378 & 0,326 & 0,244 & 0,219 & 0,139 & 0,084 & 0,101 & 0,166 & 0,128 & 0,141 & 0,145 & - \\
\hline
\end{tabular}

De forma geral, os resultados para o fluxo Brasil-China não revelam um perfil de comércio intraindustrial elevado entre os países, levando em conta a seleção de setores da pesquisa. O índice GL médio da seleção de dados foi de 0,229 para todo o período analisado, caracterizando predominância do fluxo de comércio interindustrial entre as duas economias, para os setores abordados. Os baixos índices GL para Brasil eChina seguem a pesquisa de Caldarelli e Miranda (2009), que identificou o fluxo entre os dois países como sendo preponderantemente de perfil interindustrial.

O comportamento dos índices GL para os setores selecionados, com o terceiro país do grupo de economias em desenvolvimento, México, consta na Tabela 04. De forma semelhante ao perfil com a Argentina, os fluxos Brasil-México têm destaque de índice GL médio ao longo dos anos nos capítulos 30 (produtos farmacêuticos), 85 (máquinas, aparelhos e materiais elétricos) e 90 (instrumentos e aparelhos de ótica e médico-cirúrgicos). A situação líquida de comércio, contudo, é favorável ao México, pois nos três setores o Brasil mais importa da economia mexicana que para ela exporta. 
TABELA 04 - ÍNDICES GL, POR CAPÍTULOS DO SH, NO COMÉRCIO ENTRE BRASIL E MÉXICO (1997-2013)

\begin{tabular}{|c|c|c|c|c|c|c|c|c|c|c|c|c|c|c|c|c|c|c|}
\hline Cap. & 1997 & 1998 & 1999 & 2000 & 2001 & 2002 & 2003 & 2004 & 2005 & 2006 & 2007 & 2008 & 2009 & 2010 & 2011 & 2012 & 2013 & Média $^{1}$ \\
\hline 30 & 0,420 & 0,498 & 0,509 & 0,745 & 0,698 & 0,794 & 0,965 & 0,899 & 0,867 & 0,701 & 0,701 & 0,829 & 0,670 & 0,762 & 0,837 & 0,907 & 0,906 & 0,711 \\
\hline 84 & 0,881 & 0,793 & 0,785 & 0,612 & 0,622 & 0,542 & 0,492 & 0,395 & 0,411 & 463 & 0,444 & 0,489 & 558 & 0,500 & 0,471 & 0,524 & 0,616 & 0,559 \\
\hline 85 & 0,298 & 0,447 & 0,946 & 0,937 & 0,915 & 0,876 & 0,807 & 0,895 & 0,853 & 0,677 & 0,690 & 0,520 & 0,657 & 0,445 & 0,471 & 0,547 & 0,465 & 0,657 \\
\hline 87 & 0,977 & 0,497 & 0,100 & 0,125 & 0,237 & 0,141 & 0,080 & 0,044 & 0,075 & 0,308 & 0,546 & 0,901 & 0,867 & 0,855 & 0,562 & 0,408 & 0,485 & 0,300 \\
\hline 88 & 0,000 & 0,000 & 0,000 & 0,000 & 0,000 & 0,000 & 0,000 & 0,000 & 0,005 & 0,142 & 0,000 & 0,011 & 0,820 & 0,725 & 0,422 & 0,225 & 0,957 & 0,386 \\
\hline 90 & 0,791 & 0,942 & 0,957 & 0,864 & 0,910 & 0,740 & 0,868 & 0,971 & 0,929 & 0,822 & 0,916 & 0,634 & 0,704 & 0,747 & 0,667 & 0,522 & 0,407 & 0,783 \\
\hline Média $^{2}$ & 0,561 & 0,530 & 0,549 & 0,547 & 0,564 & 0,515 & 0,535 & 0,534 & 0,523 & 0,519 & 0,549 & 0,564 & 0,713 & 0,673 & 0,572 & 0,522 & 0,639 & - \\
\hline
\end{tabular}

Fonte: elaborado pelos autores. Origem bruta dos dados: ALICEWEB (2016)

Notas: (1) Média por capítulo, ponderada pela participação no comércio bilateral, no período 1997-2013; (2) Média por ano, entre os capítulos selecionados.

Mesmo não existindo um amplo acordo preferencial de comércio entre Brasil e México ${ }^{20}$, que poderia estimular ainda mais o comércio intraindustrial, vide Silva et al. (2010), o nível geral de CII entre os dois países, para o período analisado, foi de 56,50\%. Este volume de CII superou o verificado entre Brasil-Argentina, evidenciando o México como o país do grupo de economias em desenvolvimento com maiores níveis de comércio intraindustrial com a economia brasileira. Em adição, períodos com elevado nível de CII podem ser destacados: na indústria de máquinas, entre 1999 e 2005 experimentou-se volume intenso de comércio intraindustrial na relação Brasil-México, setor que fora analisado com ênfase durante as negociações pelas duas nações entre 1999-2002 no estabelecimento e firmação do ACE no 5321; na indústria de veículos automóveis, níveis consideráveis de CII foram registrados no período 2008-2010, setor em que vigora um acordo à concessão de preferências tarifárias no intercâmbio entre os países (MDIC, 2016).

Em relação ao grupo de países desenvolvidos, formado por Alemanha e Estados Unidos, na Tabela 05 são demonstrados os índices GL para o comércio entre Brasil e Alemanha. Considerando a média dos anos, percebe-se que apenas o capítulo 8722 teve índice superior a 0,500 - setor que, em 2005, chegou no auge de CII para os anos observados, com GL igual a 0,984. De forma agregada, o Brasil foi um importador líquido da Alemanha no período e áreas consideradas, com saldo comercial negativo em torno de $\$ 65$ bilhões.

20 Os acordos entre Brasil e México se resumem aos Acordos de Complementação Econômica números 53, 54 e 55, sendo o último voltado, especificamente, ao setor automotivo (MDIC, 2016). 21 O qual estabelece preferências fixas entre Brasil-México.

22 Veículos automóveis, tratores, e outros veículos terrestres. 
TABELA 05 - ÍNDICES GL, POR CAPÍTULOS DO SH, NO COMÉRCIO ENTRE BRASIL E ALEMANHA (1997-2013)

\begin{tabular}{|c|c|c|c|c|c|c|c|c|c|c|c|c|c|c|c|c|c|c|}
\hline Cap. & 1997 & 1998 & 1999 & 2000 & 001 & 2002 & 2003 & 2004 & 2005 & 2006 & 2007 & 2008 & 2009 & 2010 & 2011 & 2012 & 2013 & Média $^{1}$ \\
\hline 30 & 13 & 0,01 & 14 & 0 & 014 & 0,034 & 068 & 0,194 & 409 & 0,144 & 027 & 094 & 0,109 & 0,077 & 0,064 & 006 & 0,008 &, 068 \\
\hline 84 & 260 & 0,331 & 0,327 & 0,400 & 337 & 0,398 & 0,522 & 0,565 & 0,498 & 0,520 & 0,461 & 0,384 & 0,269 & 0,326 & 0,316 & 0,329 & 0,294 & 0,382 \\
\hline 85 & 164 & 0,152 & 0,161 & 0,187 & 0,186 & 0,284 & 0,341 & 0,559 & 0,581 & 0,550 & 0,491 & 0,438 & 0,466 & 0,377 & 0,411 & 0,405 & 0,397 & 0,356 \\
\hline 87 & 0,362 & 0,477 & 0,385 & 0,286 & 0,245 & 0,257 & 0,342 & 0,465 & 0,984 & 0,961 & 0,960 & 0,920 & 0,831 & 0,537 & 0,195 & 0,189 & 0,154 & 0,725 \\
\hline 88 & 0,189 & 0,102 & 0,494 & 0,867 & 0,173 & 0,214 & 0,455 & 0,833 & 0,200 & 0,649 & 0,487 & 0,958 & 0,226 & 0,646 & 0,273 & 0,272 & 0,691 & 0,458 \\
\hline 90 & 0,059 & 0,055 & 0,068 & 0,088 & 0,063 & 0,073 & 0,100 & 0,074 & 0,081 & 0,109 & 0,101 & 0,073 & 0,072 & 0,098 & 0,092 & 0,076 & 0,070 & 0,081 \\
\hline Média² & 180 & 0,188 & 242 & 0,307 & 170 & 0,210 & 304 & 0,448 & 0,459 & 489 & 0,421 & 0,478 & 0,329 & 344 & 0,225 & 213 & 0,269 & 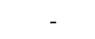 \\
\hline
\end{tabular}

Fonte: elaborado pelos autores. Origem bruta dos dados: ALCEWEB (2016)

Notas: (1) Média por capítulo, ponderada pela participação no comércio bilateral, no período 1997-2013; (2) Média por ano, entre os capítulos selecionados.

Na Tabela 05 denota-se claramente o perfil de comércio entre Brasil-Alemanha ser mais orientado ao tipo interindustrial, aquele realizado entre distintas indústrias. Mesmo em 2006, quando o índice médio atingiu seu pico entre cada um dos anos $(0,489)$, o nível de CII não excedeu a marca dos 50\%. No entanto, períodos com destaque no CII podem ser apontados, como o compreendido entre 2005 e 2010, na indústria de veículos automóveis, ou nos anos 2000 e2008, para a indústria de aeronaves e aparelhos espaciais.

Por fim, os índices GL para a relação Brasil-EUA estão representados na Tabela 06. Com este país, três setores têm maior relevância no sentido de elevados níveis de CII: o de máquinas, aparelhos e materiais elétricos, reatores nucleares, caldeiras, máquinas, aparelhos e instrumentos mecânicos e o de veículos automóveis, tratores e outros veículos terrestres. Os dois primeiros setores apresentaram comportamento crescente de CII, entre 1997 e 2013, enquanto o último apresentou índice decrescente.

TABELA 06 - ÍNDICES GL, POR CAPÍTULOS DO SH, NO COMÉRCIO ENTRE BRASIL E ESTADOS UNIDOS (1997-20 13)

\begin{tabular}{|c|c|c|c|c|c|c|c|c|c|c|c|c|c|c|c|c|c|c|}
\hline Cap. & 1997 & 1998 & 1999 & 2000 & 2001 & 2002 & \begin{tabular}{|l|l|}
2003 \\
\end{tabular} & \begin{tabular}{|l|}
2004 \\
\end{tabular} & 2005 & 2006 & 2007 & 2008 & \begin{tabular}{|l|l|}
2009 \\
\end{tabular} & 2010 & 2011 & 2012 & 2013 & Média $^{1}$ \\
\hline 30 & \begin{tabular}{|l|}
0,022 \\
\end{tabular} & 0,048 & 0,018 & 0,021 & 0,023 & 0,046 & 0,042 & 0,138 & 0,240 & 0,197 & 0,226 & 0,246 & 0,236 & 0,210 & 0,233 & 0,232 & 0,220 & 0,170 \\
\hline 84 & 0,569 & 0,557 & 0,617 & 0,574 & 0,527 & 0,746 & 0,852 & 0,878 & 0,932 & 0,919 & 0,724 & 0,558 & 0,445 & 0,507 & 0,538 & 0,529 & 0,581 & 0,646 \\
\hline 85 & 0,390 & 0,396 & 0,377 & 0,492 & 0,660 & 0,829 & 0,985 & 0,820 & 0,918 & 0,978 & 0,887 & 0,797 & 0,740 & 0,507 & 0,496 & 0,656 & 0,436 & 0,650 \\
\hline 87 & 0,902 & 0,943 & 0,680 & 0,590 & 0,475 & 0,314 & 0,371 & 0,467 & 0,453 & 0,564 & 0,654 & 0,939 & 0,785 & 0,614 & 0,629 & 0,657 & 0,560 & 0,566 \\
\hline 88 & 0,763 & 0,522 & 0,343 & 0,303 & 0,210 & 0,151 & 0,191 & 0,235 & 0,336 & 0,592 & 0,609 & 0,779 & 0,937 & 0,705 & 0,753 & 0,984 & 0,859 & 0,453 \\
\hline 90 & 0,163 & 0,263 & 0,435 & 0,421 & 0,380 & 0,407 & 0,331 & 0,275 & 0,263 & 0,244 & 0,230 & 0,177 & 0,149 & 0,137 & 0,143 & 0,163 & 0,146 & 0,237 \\
\hline Média $^{2}$ & 0,468 & 0,455 & 0,412 & 0,400 & 0,379 & 0,415 & 0,462 & 0,469 & 0,523 & 0,582 & 0,555 & 0,583 & 0,549 & 0,447 & 0,465 & 0,537 & 0,467 & - \\
\hline
\end{tabular}

De maneira similar ao resultado médio encontrado para Brasil-Alemanha, o índice GL médio entre Brasil-EUA denota, também, preponderância de fluxos comerciais interindustriais nas relações entre os dois países. Verifica-se que os maiores índices GL encontram-se na indústria de transformação, o que condiz com as constatações de Moreira e De Paula (2010) - de que o nível de CII entre Brasil e EUA é mais intenso em produtos utilizados à elaboração de outros produtos. 
Nas transações entre Brasil e EUA, verificou-se que o CII ocorre basicamente em torno de produtos da indústria de transformação. Em nível geral, além da seleção estabelecida no objetivo deste trabalho, ou seja, na totalidade do fluxo comercial Brasil-Estados Unidos, seguindo a agregação de dados a dois dígitos do SH, há fortes indícios de comércio intraindustrial. Apesar do que é encontrado em Loertscher e Wolter (1980) e Helpman (1987), a pesquisa demonstrou que é possível a existência de CII entre uma nação desenvolvida e outra em desenvolvimento, em determinadas indústrias, mesmo na presença de divergentes estágios de desenvolvimento de cada uma e de disparidades no PIB per capita. As indústrias em evidência, sob o índice GL, para Brasil e EUA, parecem convergir ao apontado em análise similar de Moreira e De Paula (2010), de que o CII pode atuar como mecanismo para o progresso técnico. Considerando o Brasil um país em desenvolvimento, o comércio intraindustrial, nestas circunstâncias, pode influenciar a consolidação de uma base cumulativa de conhecimentos mais complexos e a aquisição progressiva de competências tecnológicas próprias por parte da indústria nacional, visto que, conforme o relatório do Banco Mundial (2008), a melhoria das tecnologias nos países em desenvolvimento depende parcialmente dos países mais avançados, ou seja, parte do progresso tecnológico nas economias em desenvolvimento é na verdade um processo de adaptação aos lançamentos vindouros das economias desenvolvidas.

Os índices calculados demonstram que com a China, um dos principais parceiros comerciais do Brasil, o fluxo é basicamente interindustrial nas categorias de produto analisadas, categorias estas que o Brasil se posiciona na condição de importador líquido, tal qual verificado no trabalho de Caldareli e Miranda (2009). Observa-se, nas indústrias intensivas em alta tecnologia, como a de produtos farmacêuticos e de instrumentos e aparelhos de ótica, pelos baixos índices GL encontrados, a condição do Brasil de importador líquido na ordem de US $\$ 7,50$ bilhões na relação Brasil-Alemanha e de US $\$ 9,72$ bilhões na relação Brasil-EUA - ou seja, não há CII para os capítulos 30 e 90, com o grupo de países desenvolvidos. Em contrapartida, o CII de produtos farmacêuticos é intenso com os países latino americanos em desenvolvimento, verificando, desta maneira, que os níveis de comércio intraindustrial podem se intensificar em determinadas indústrias, a partir da criação de acordos comerciais preferenciais, como previram alguns estudos (CARMO; BITTENCOURT, 2013; MONTORO et al., 2005; SILVA et al., 2010).

Abondados os perfis de comércio brasileiro com os países selecionados (Argentina, China e México, além de Alemanha e Estados Unidos), nos diferentes capítulos definidos da estrutura $\mathrm{SH}$, o artigo tem continuidade com as principais conclusões obtidas pelos autores.

\section{CONCLUSÕES}

Apesar da restrição no tocante a quantidade de nações representantes dos dois contextos econômicos distintos, o artigo não se limitou a analisar os fluxos de comércio do Brasil com um único país (do gênero bilateral), realizando, assim, 
esforços iniciais para estratificação de padrões do comércio de uma nação para com determinados contextos econômicos distintos. Nesta pesquisa, por meio do índice GL, observou-se a não existência de rigoroso padrão nos níveis de comércio intraindustrial entre Brasil e o grupo de países desenvolvidos (Alemanha e Estados Unidos) ou entre o grupo de países em desenvolvimento (Argentina, China e México), considerando a amostra de produtos selecionados, no período 1997-2013.

Apesar de não constatado um padrão de comércio intraindustrial na pauta comercial com os grupos países de desenvolvidos e em desenvolvimento, algumas questões observadas são plausíveis de serem salientadas: i) CII próximo da totalidade na indústria de automóveis, dentre outros, entre Brasil e Argentina; ii) níveis intensos de CII entre Brasil e Alemanha, também na indústria de veículos automóveis, entre 2005 e 2010, declinando de forma abrupta desde então; iii) níveis consideráveis de CII entre Brasil e México na indústria de máquinas, entre 1999-2005, com sinalização de declínio nos anos mais recentes; iv) elevados índices GL na indústria de aeronaves e suas partes, no fluxo Brasil-EUA, entre 2007 e 2013. Situações específicas como estas carecem de maior discussão à luz da teoria do comércio internacional e, especificamente, do comércio intraindustrial, em especial com nações como Alemanha e México, parceiros comerciais que não figuram como objetos constantes de estudo na literatura envolvendo a temática do CII.

O artigo não tem qualquer pretensão de esgotar o assunto, uma vez que se trata de um tema com vastas possibilidades ainda a serem exploradas. O índice GL, apesar de frágil em determinados aspectos, ainda continua sendo um método amplamente aceito pela literatura da área para a mensuração do comércio intraindustrial. Como sugestão de continuidade da pesquisa, entretanto, propõese a avaliação de quanto o comércio intraindustrial, medido por índices GrubelLloyd, contribui para o aumento da pauta total de comércio internacional do Brasil com os países já estudados, por meio da abordagem proposta por Menon e Dixon, na década de 1990. Não obstante, a análise de comércio intraindustrial dos tipos vertical e horizontal apresenta-se como outra forma de continuidade do trabalho, bem como uma estimação apurada dos determinantes do CII, por meio de regressões utilizando dados em painel. Por fim, outra refinação da análise consiste na maior desagregação dos códigos de produtos, a exemplo da utilização da nomenclatura SITC, a três dígitos.

\section{REFERÊNCIAS}

ALICEWEB (2016). "Sistema de Análise das Informações de Comércio Exterior". URL: http:// aliceweb.mdic.gov.br/ / index/home. Acesso em: 20 de fevereiro 2016.

ANAM, M. \& CHIANG, S-H. Chiang (2003). Intraindustry trade in identical products: a portfolio approach. Review of International Economics, 11, pp. : 90 -100 . 
ANDRESSEN, M. A. (2003). "Empirical intra-industry trade: what we know and what we need to know.” Burnaby: Simon Fraser University.

AQUINO, A. (1978). "intraIntra-industry trade and inter-industry trade specialization as concurrent sources of international trade in manufactures,". Weltwirtschaftliches Archiv, 114(2): 275-296.

ARMINGTON, P. S. (1969). "Aa theory of demand for products distinguished by place of production”. IMF Staff Papers, 16(1): 159-178.

BALASSA, B (1965). eEconomic development and integration. Mexico, D.F.: Centro de Estudios Monetarios Latinoamericanos, 1965.

BALASSA, B (1966). "tTariff reductions and trade in manufactures among the industrial countries.," American Economic Review, J une 1966, 56 (2), ):pp. 466-473.

BALASSA, B. (1966). "Tariff reductions and trade in manufacturers among the industrial countries." The American Economic Review, 56 (3): 466-473.

BALASSA, B. (1977). “'Revealed' comparative advantage revisited: an analysis of relative export shares of the industrial countries, 1953- 1971." The Manchester School, 45 (4): 327-344.

BALTAR, C. T. (2008). "Comércio exterior inter e intra-industrial: Brasil 20032005. " Economia e Sociedade, 17 (32): 107-132.

BANCO MUNDIAL (2008). “Global economic prospects 2008: technology diffusion in the developing world. Global Economic Prospects and the Developing Countries (GEP)". URL: http:// documents.worldbank.org/ curated/ en/ 2008/01/9013126/ globaleconomic-prospects-technology-diffusion-developing-world-2008. Acesso em: 14 de janeiro de 2016.

BITTENCOURT, M. V. L. \& CARMO, A. S. \&THOMPSON, S. R. (2015). “What can be said about trade quality between Brazil and main developed countries?". Porto Alegre: XVIII Encontro de Economia da Região Sul.

BORGES, C. V. C. \& FRAGA, G. J . (2015). “Integração comercial da região Sul com o BRICS: uma análise através de indicadores tradicionais de comércio internacional entre 2000 e 2012". Acta Scientiarum, 37 (1): 41-52.

CALDARELLI, C. E. \& MIRANDA, S. H. G. de (2009). "Restrições comerciais e comércio intra-industrial: uma análise usando modelo LOGIT. " Porto Alegre: 470 Congresso SOBER. 
CAMPOS, M. de F. S. de S. \& HIDALGO, Á. B. \& MATA, D. da (2007). "Comércio intra-indústria e desigualdade de rendimentos nas firmas da indústria brasileira. " Revista EconomiA, 8 (4): 97-122.

CARMO, A. S. \& BITTENCOURT, M. V. L. (2013). “Comércio intraindustrial entre o Brasil e Argentina: novas evidências. " Revista de Economia e Administração, 12 (1): 7-31.

DIXIT, A. K. \& GROSSMAN, G. M. Grossman (1982). Trade and protection with multistage production. Review of Economic Studies, 43, pp.: 583--594.

DREZE, J . (1961). Les Eexportations intra-C.E.E. in 1958 et la position Belge. Recherches Economiques de Louvain, 1961, 27, : 717-738.

EGGER, H. \& EGGER, P. \& GREENAWAY, D. (2007). “Intra-industry trade with multinational firms." European Economic Review, 51: 1959- 1984.

FALVEY, R. E. (1981). “Commercial policy and intra-industry trade.” J ournal of International Economics, 11: 495-511.

FALVEY, R. E. (1981). Commercial policy and intra-industry trade. J ournal of International Economics, 11, pp. : 495- 511.

Finger, J . M. (1975). “Trade oOverlap and Intraintra-Industry industry Tradetrade". Economic Inquiry, 13(4): 581-589.

FONTAGNÉ, L. \& FREUDENBERG, M. (1997). “Intra-industry trade: methodological issues reconsidered." CEPII, Document de travail n. 97-01.

GREENAWAY, D. \& MILNER, C. (1983). “On the measurement of intraindustry trade." The Economic J ournal, 93 (372): 900-908.

GRUBEL, H. G. \&J OHNSON, H. G. (1967). “Nominal tariffs, indirect taxes and effective rates of protection: the common market countries 1959". The Economic J ournal, 77 (308): 761-776.

GRUBEL, H. G. \& LLOYD, P. J . (1987). Intra-industry trade: the theory and measurement of international trade in differentiated products. Londres: Macmillan.

HELPMAN, E. (1987). “Imperfect competition and international trade: evidence from fourteen industrial countries." J ournal of the J apanese and International Economies, 1: 62-81. 
HIDALGO, Á. B. (1993a). “Mudanças na estrutura do comércio internacional brasileiro: comércio interindústria x comércio intra-indústria. " Análise Econômica, 11 (20): 66-68.

HIDALGO, Á. B. (1993b). “O intercâmbio comercial brasileiro intra-indústria: uma análise entre indústrias e entre países. " Revista Brasileira de Economia, 47 (2): 243-264.

HILDGERT, F. (1935)., "tThe approach to bilateralism: a change in the structure of World trade,". Stockholm: Svenska Handelsbank Index:, 1935, pp. 175-188.

KÁDÁR, B. (1981). “On the economics of intra-industry trade.” J ournal of Economic Literature, 91 (3): 1109-1111.

KRUGMAN, P. (1979), "iIncreasing returns, monopolistic competition, and international trade., "J ournal of International Economics, November1979, 9 (4), pp.: 469-479.

KRUGMAN, P. R. (1981). "Intraindustry specialization and the gains from trade." The J ournal of Political Economy, 89 (5): 959-973.

LANCASTER, K. (1979)., Variety, equity, and efficiency. Oxford: Basil Blackwell, 1979.

LINDER, S. (1961). An essay on trade and transformation. New York: J ohn Wiley.

LINDER, S. B. (1961)., An essay on trade and transformation., New York: J ohn Wiley, 1961.

LLOYD, P. J . (2004)., "Hhow intra-industry trade changed our perception of the world World economy.," Singapore Economic Review, 49 (1), 2004, pp. 1-17.

LOERTSCHER, R. \& WOLTER, F. (1980). “Determinants of intra-industry trade: among countries and across countries." Weltwirtschaftliches Archiv, 116 (2): 280-293.

MARKUSEN, J . R. \& VENABLES, A. J . (2000). “The theory of endowment, intra-industry and multi-national trade." J ournal of International Economics, 52: 209-234.

MDIC (2016). “Negociações Internacionais - DEINT.” URL:

http:// www.desenvolvimento.gov.br/ sitio/ interna/interna.php?area $=5 \& m e n u=$ 405. Acesso em: 2o de fevereiro de 2016. 
MONTORO, F. \& VARTANIAN, P. R. \& CURZEL, R. (2005). “Uma investigação da evolução do comércio intra-indústria na relação Brasil-MERCOSUL no período 1996-2005: o que revelam os dados? " São Paulo: Seminários NESPI.

MOREIRA, T. \& DE PAULA, N. (2010). "Evolução do comércio intraindustrial entre Brasil e Estados Unidos no período 1997-2008. " Revista de Economia, 36 (3): 95-109.

PINTO, P. B. O. \&VASCONCELOS, C. R. F. \& FREGUGLIA, R. da. S. (2012). "Comércio intra-indústria: análise da hipótese de ajuste suavizado para o Brasil. "Porto de Galinhas: 40ํㅡㄹ Encontro Nacional de Economia.

RAYMENT, P. B. W. (1983). "Intra- "industry" specialization and the foreign trade of industrial countries". Controlling Industrial Economies, Essays in Honour of C. T. Saunders: , London: Macmillan, 1983, pp. 1-28.

SCOTT, M. F. G. (1975). "Intra-industry trade: the theory and measurement of International trade in differentiated products." The Economic J ournal, 85 (339): 646-648.

SILVA, A. F. \& SILVA, O. M. da \&ZILLI, J . B. (2010). “Evolução e contribuição do comércio intra-indústria para o crescimento do comércio total entre Brasil e Angentina. " Revista de Economia, 36 (2): 7-24.

VASCONCELOS, C. R. F. (2003). “O comércio Brasil-Mercosul na década de 90: uma análise pela ótica do comércio intra-indústria. " Revista Brasileira de Economia, 57 (1): 283-313. 


\section{APÊNDICES}

Apêndice A - Principais parceiros comerciais brasileiros

Tabela A - RANKING DOS PRINCIPAIS PARCEIROS COMERCIAIS BRASILEIROS, EM 2013

\begin{tabular}{l|c|c|c}
\hline \multicolumn{1}{c|}{ País } & Posição & $\begin{array}{c}\text { Volume total de comércio } \\
\text { (em US\$ bilhões) }\end{array}$ & $\begin{array}{c}\text { Participação na } \\
\text { corrente de comércio } \\
\text { brasileira (em \%) }\end{array}$ \\
\hline China & $1^{\underline{o}}$ & 83,33 & 17,3 \\
\hline Estados Unidos & $2^{\underline{o}}$ & 60,65 & 12,59 \\
\hline Argentina & $3^{\underline{o}}$ & 36,08 & 7,49 \\
\hline Alemanha & $4^{\underline{o}}$ & 21,73 & 4,51 \\
\hline Países Baixos (Holanda) & $5^{\underline{o}}$ & 19,67 & 4,08 \\
\hline Japão & $6^{\underline{o}}$ & 15,05 & 3,12 \\
\hline Coréia do Sul & $7^{\underline{o}}$ & 14,21 & 2,95 \\
\hline Itália & $8^{\underline{o}}$ & 10,81 & 2,24 \\
\hline Nigéria & $9^{\underline{o}}$ & 10,52 & 2,08 \\
\hline México & $10^{\underline{o}}$ & 10,03 & \\
\hline
\end{tabular}

Fonte: elaborado pelos autores. Origem bruta dos dados: ALICEWEB (2016)

\section{Apêndice B - Estrutura de comércio dos capítulos analisados}

TABELA B - ESTRUTURA DE COMÉRCIO DOS CAPÍTULOS ANALISADOS, ENTRE 1997-2013 (EM US\$ BILHÕES)

\begin{tabular}{|c|c|c|c|c|c|c|c|c|c|c|c|c|c|c|c|}
\hline \multirow{2}{*}{ Capítulo } & \multicolumn{3}{|c|}{ Alemanha } & \multicolumn{3}{|c|}{ Argetina } & \multicolumn{3}{|c|}{ China } & \multicolumn{3}{|c|}{ Estados Unidos } & \multicolumn{3}{|c|}{ México } \\
\hline & $\mathrm{X}$ & M & $\%$ & $\mathrm{X}$ & M & $\%$ & $\mathrm{X}$ & $\mathrm{M}$ & $\%$ & $\mathrm{X}$ & M & $\%$ & $\mathrm{X}$ & $\mathrm{M}$ & $\%$ \\
\hline 33 & 0,25 & 7,75 & 3,55 & 1,77 & 1,64 & 0,96 & 0,15 & 0,41 & 0,13 & 1,15 & 10,87 & 1,89 & 0,95 & 0,96 & 2,17 \\
\hline 84 & 8,98 & 39,52 & 21,55 & 21,77 & 7,17 & 8,20 & 3,07 & 41,42 & 9,91 & 33,52 & 72,12 & 16,58 & 9,55 & 3,39 & 14,69 \\
\hline 85 & 3,28 & 13,54 & 7,47 & 15,14 & 2,31 & 4,95 & 1,08 & 63,59 & 14,41 & 18,24 & 36,22 & 8 & 2,58 & 5,43 & 9,09 \\
\hline 87 & 6,53 & 16,66 & 10,30 & 60,33 & 54,96 & 32,66 & 0,91 & 5,66 & 1,46 & 12,69 & 8,98 & 3,40 & 17,85 & 12,80 & 34,79 \\
\hline 88 & 1,60 & 0,66 & 1,01 & 0,86 & 0,00 & 0,25 & 3,06 & 0,00 & 0,68 & 25,87 & 11,45 & 5,86 & 0,95 & 0,14 & 1,24 \\
\hline 90 & 0,37 & 8,68 & 4,02 & 1,52 & 0,75 & 0,64 & 0,23 & 7,29 & 1,68 & 2,44 & 19,10 & 3,38 & 0,50 & 0,79 & 1,46 \\
\hline
\end{tabular}

Fonte: elaborado pelos autores. Origem bruta dos dados: ALICEWEB (2016)

Notas: X) exportações brasileiras; M) importaçoes brasileiras; 5) percentual sobre o comércio bilateral total 


\section{Apêndice C - Balança comercial brasileira, com os países investigados}

\section{TABELA C - BALANÇA COMERCIAL ENTRE BRASIL E PARCEIROS COMERCIAIS SELECIONADOS (EM US\$ BILHÕES)}

\begin{tabular}{|c|c|c|c|c|c|c|c|c|c|c|c|c|c|c|c|}
\hline \multirow{2}{*}{ Ano } & \multicolumn{3}{|c|}{ Alemanha } & \multicolumn{3}{|c|}{ Argetina } & \multicolumn{3}{|c|}{ China } & \multicolumn{3}{|c|}{ Estados Unidos } & \multicolumn{3}{|c|}{ México } \\
\hline & $\mathrm{X}$ & M & Saldo & $\mathrm{X}$ & M & Saldo & $\mathrm{X}$ & M & Saldo & $\mathrm{X}$ & M & Saldo & $\mathrm{X}$ & M & Saldo \\
\hline 1997 & 2,61 & 4,96 & $-2,35$ & 6,77 & 7,94 & $-1,17$ & 1,09 & 1,17 & $-0,08$ & 9,27 & 13,71 & $-4,43$ & 0,83 & 1,17 & $-0,34$ \\
\hline 1998 & 3,01 & 5,25 & $-2,25$ & 6,75 & 8,02 & $-1,28$ & 0,90 & 1,03 & $-0,13$ & 9,75 & 13,51 & $-3,77$ & 1,00 & 0,98 & 0,02 \\
\hline 1999 & 2,54 & 4,77 & $-2,22$ & 5,36 & 5,81 & $-0,45$ & 0,68 & 0,87 & -0 & 10,68 & 11,74 & $-1,07$ & 1,07 & 0,62 &, 45 \\
\hline 2000 & 2,53 & 4,43 & $-1,90$ & 6,24 & 6,84 & $-0,61$ & 1,09 & 1,22 & $-0,14$ & 13,19 & 12,90 & 0,29 & 1,71 & 0,75 & 0,96 \\
\hline 2001 & 2,50 & 4,83 & $-2,32$ & 5,01 & 6,21 & $-1,20$ & 1,90 & 1,33 & 0,57 & 14,21 & 12,91 & 1,30 & 1,87 & 0,70 & 1,18 \\
\hline 2002 & 2,54 & 4,42 & $-1,88$ & 2,35 & 4,74 & $-2,40$ & 2,52 & 1,55 & 0,97 & 15,38 & 10,29 & 5,09 & 2, & 0,58 & 1,77 \\
\hline 2003 & 3,14 & 4,20 & $-1,06$ & 4,57 & 4,67 & $-0,10$ & 4,53 & 2,15 & 2,39 & 16,73 & 9,57 & ,16 & 2,75 & 0,53 & 2,21 \\
\hline 2004 & 4,05 & 5,07 & $-1,03$ & 7,39 & 5,57 & 1,82 & 5,44 & 3,71 & 1,73 & 20,10 & 11,36 & ,74 & 3,96 & 0,70 & 3,25 \\
\hline 2005 & 5,03 & 6,14 & $-1,11$ & 9,93 & 6,24 & 3,69 & 6,83 & 5,35 & 1,48 & 22,54 & 12,67 & 9,87 & 4,07 & 0,84 & 3,23 \\
\hline 2006 & 5,69 & 6,50 & $-0,81$ & 11,74 & 8,05 & 3,69 & 8,40 & 7,99 & 0,41 & 24,52 & 14,66 & 9,87 & 4,46 & 1,31 & 3,15 \\
\hline 2007 & 7,21 & 8,67 & $-1,46$ & 14,42 & 10,40 & 4,01 & 10,75 & 12,62 & $-1,87$ & 25,07 & 18,72 & 4 & 4,26 & 1,98 & 2,28 \\
\hline 2008 & 8,85 & 12,03 & $-3,18$ & 17,61 & 13,26 & 4,35 & 16,52 & 20,04 & $-3,52$ & 27,42 & 25,63 & 1,80 & 4,28 & 3,13 & 1,16 \\
\hline 2009 & 6,17 & 9,87 & $-3,69$ & 12,78 & 11,28 & 1,50 & 21,00 & 15,91 & 5,09 & 15,60 & 20,03 & $-4,43$ & 2,68 & 2,78 & $-0,11$ \\
\hline 2010 & 8,14 & 12,55 & $-4,42$ & 18,52 & 14,43 & 4,09 & 30,79 & 25,60 & 5,19 & 19,31 & 27,04 & $-7,74$ & 3,72 & 3,86 & $-0,14$ \\
\hline 2011 & 9,04 & 15,21 & $-6,17$ & 22,71 & 16,91 & 5,80 & 44,31 & 32,79 & 11,52 & 25,80 & 33,97 & $-8,17$ & 3,96 & 5,13 & $-1,17$ \\
\hline 2012 & 7,28 & 14,21 & $-6,93$ & 18,00 & 16,44 & 1,55 & 41,23 & 34,25 & 6,98 & 26,70 & 32,36 & $-5,66$ & 4,00 & 6,07 & $-2,07$ \\
\hline 2013 & 6,55 & 15,18 & $-8,63$ & 19,62 & 16,46 & 3,15 & 46,03 & 37,30 & 8,72 & 24,65 & 36,02 & $-11,37$ & 4,23 & 5,79 & $-1,56$ \\
\hline
\end{tabular}

Fonte: elaborado pelos autores. Origem bruta dos dados: ALICEWEB (2016)

Notas: X) exportações brasileiras; M) importaçoes brasileiras. 